\title{
Human Herpesvirus 1 Antibody
}

National Cancer Institute

\section{Source}

National Cancer Institute. Human Herpesvirus 1 Antibody. NCI Thesaurus. Code

C118488.

Any immunoglobulin that recognizes the human herpesvirus 1. 